\title{
NEUČINKOVITOST VOJSKE KOT POKAZATEL NEUSTREZNOSTI CIVILNEGA NADZORA (2)
}

\author{
INEFFECTIVENESS OF THE MILITARY AS AN \\ INDICATOR OF INAPPROPRIATE CIVILIAN \\ CONTROL (2)
}

Povzetek Prispevek je nadaljevanje analize o vzročno-posledični povezavi med civilnim nadzorom in učinkovitostjo vojske. V prvem delu je bil predstavljen teoretičnometodološki okvir analize, $\mathrm{v}$ tem delu pa avtor predstavlja rezultate raziskave o stanju civilno-vojaških odnosov v Republiki Sloveniji ter vplivih civilnega nadzora na učinkovitost Slovenske vojske.

Raziskava je pokazala, da se v Sloveniji uveljavlja praksa civilnega nadzora nad oboroženimi silami po vzoru drugih demokratičnih držav, vendar problematika prve generacije civilno-vojaških odnosov še ni končana. Uveljavljanje nadzora v praksi zagotavlja podrejenost vojske civilnim oblastem, pri čemer mehanizmi nadzora ne krepijo sposobnosti Slovenske vojske, da učinkovito izpolni svoje poslanstvo. Posledično lahko povzročijo nezadovoljstvo vojske ali izgubo kredibilnosti v javnosti.

Ključne besede

Abstract

\section{Civilni nadzor, učinkovitost vojske, Slovenska vojska.}

This article is a continuation of the analysis of cause-effect relations between civilian control and military effectiveness. The first part presented the theoretical and methodological framework, while in the second part, the author presents the results of the study of civil-military relations in the Republic of Slovenia, focusing on the impact of civilian control on the effectiveness of the Slovenian Armed Forces.

The study showed that the practice of civilian control over the armed forces in Slovenia follows the example of those in other democratic states. However, the issue of the first-generation civil-military relations has not yet been completed. The enforcement of civilian control in practice provides for a complete subordination 
of the military to civilian authorities; however, it does not contribute to the ability of the military to effectively execute its missions. Rather, civilian control can cause military dissatisfaction and reluctance, as well as loss of credibility with the society.

\section{Key words Civilian control, military effectiveness, Slovenian Armed Forces.}

Uvod Demokratični procesi v postkomunističnih (tranzicijskih) državah in vzpostavljanje demokratičnega civilnega nadzora nad oboroženimi silami so bili predmet preučevanja mnogih avtorjev. Začetna cilja demokratičnih naporov sta bila dosledna podreditev vojske civilistom in preprečitev vmešavanja v politiko (Cottey, Edwards in Forster, 2002, Cottey, 2000), pri čemer sta bila »transformacija« civilistov in njihova usposobljenost za učinkovito izvajanje nadzora večja problema od transformacije vojske glede na spremenjeno varnostno in politično okolje (Jelušič, 1998, Betz, 2004). Institucionalni temelji za izvajanje demokratičnega nadzora (»hardver« civilnega nadzora) so bili vzpostavljeni na hitro, demokratične norme in načela (»softver«) pa v praksi niso v celoti zaživeli (Bland, 2001). Te države so izkusile različne težave in deviacije uresničevanja demokratičnega nadzora; na primer težave sprejemanja demokratičnih norm v vojski, vojaški poskusi vplivanja na odločitve v parlamentu in izmikanje nadzoru (Boene in Bredow, 1999), posredovanje politike v oborožene sile, parapolitična dejavnost vojakov in remilitarizacija vodilnih dolžnosti v obrambni administraciji (Bebler, 1992), pomanjkanje izkušenj in interesa za izvajanje parlamentarnega nadzora (Betz, 2004), zavajanje javnosti o uporabi vojske in spori med civilnimi in vojaškimi oblastmi (Born, Caparini, Haltiner in Kuhlman, 2006), nedemokratični načini uveljavljanja civilnega nadzora ter nesposobnost vojske, da sledi novi vlogi in novim zahtevam (Jelušič, 1998).

Eno glavnih sporočil raziskovalcev je, da v tranzicijskih državah ni glavni problem podrejanje vojske civilnim oblastem, temveč kako zagotoviti učinkovito upravljanje obrambnega in varnostnega sektorja (Cottey, Edmunds in Forster, 2002, Edmunds, 2004, Bruneau, 2009). Odstopanja od demokratičnih načel pri uresničevanju civilnega nadzora $\mathrm{v}$ praksi so bila posledica predvsem pomanjkanja izkušenj in politične kulture, šibkega parlamentarnega nadzora, majhne vloge javnosti ter avtoritativnih navad (Bebler, 1997) in okoliščin, v katerih so se znašle vojske brez močnega političnega nadzora, ki ga je pred demokratizacijo izvajala komunistična partija (Jelušič, 1998).

Predmet študije je bila tudi Slovenija, ki je uvrščena v skupino držav, ki so večinoma zaključile problematiko prve generacije civilno-vojaških odnosov (vzpostavitev normativnih in drugih podlag za izvajanje civilnega nadzora) in se spoprijemajo s problematiko druge generacije (uresničevanje nadzora v praksi). Zanjo so značilne politične razlike glede nadzora nad vojsko in oblikovanja obrambne politike, težnje po uporabi vojske $\mathrm{v}$ politične namene ter vprašanja o tem, kako zagotoviti učinkovito obrambno načrtovanje, kakovosten parlamentarni nadzor in nadzor nad obrambnim proračunom (Cottey, Edmunds in Forster, 2002). 
V dvajsetih letih razvoja demokratičnih civilno-vojaških odnosov se je Slovenija srečala s pojavi, kot so nesorazmerna moč ministra za obrambo, grožnja demokratičnemu vodenju vojske in prevzemanju poveljevanja ministra (Grizold, 1994, Hendrickson in Ethridge, 2002), spori med izvajalci nadzora in vojaško vmešavanje v civilne zadeve v javnih medijih (Malešič, 2003), nejasne in nedorečene normativne podlage ter neuravnotežene vloge pri izvajanju nadzora (Grizold, 1994 in 1997, Fekonja, 1996, Arnejčič in Vuk, 2001, Zorc, 2005), nerazumevanje vlog izvajalcev nadzora (Jelušič, 1996), nezmožnost doseganja političnega konsenza o ključnih vprašanjih nacionalne varnosti in obrambe (Grizold, 1997), pomanjkljiva civilianizacija obrambne administracije (USEUCOM, 2000) ter netransparentnost delovanja izvršilne veje oblasti in oviranje parlamentarnega nadzora (Prebilič, 2007) $)^{1}$.

Za demokratično transformacijo civilno-vojaških odnosov v Sloveniji je bilo ugotovljeno, da problemi niso izhajali iz vojaškega konservatizma, temveč političnih elit, katerih antagonistična nasprotja so upočasnila in ovirala razvoj stabilnih odnosov med vojaškimi in civilnimi institucijami (Grizold, 1997). Nekateri avtorji so opozorili na pretiran nadzor in negativne vplive, ki jih ima nadzor na delovanje Slovenske vojske, ter na omejevanje njene strokovne avtonomnosti (Kukec, 1996, USEUCOM, 2000, Greystone, 2001, Krek, 2007, Kotnik, 2007)².

V prvem delu prispevka, objavljenega v reviji Sodobni vojaški izzivi (Furlan, 2015), je bil predstavljen teoretično-metodološki pristop ugotavljanja vzročno-posledične povezave med civilnim nadzorom in učinkovitostjo vojske. $\mathrm{V}$ nadaljevanju bodo predstavljeni rezultati raziskave (Furlan, 2012), ki je bila opravljena zaradi ugotavljanja kakovosti uresničevanja civilnega nadzora v Republiki Sloveniji in njegovega vpliva na stanje in delovanje Slovenske vojske.

\footnotetext{
Minister uživa nesorazmerno moč, ker so odgovornosti glede obrambe opredeljene nejasno ali na splošno (predsednik republike je samo figura, predsednik vlade nima odgovornosti). Minister je sam določil organiziranost MO RS in praktično postal poveljnik (Grizold, 1994, 92). Malešič med »tipičnimi problemi« navaja orožarsko afero leta 1993, interpelacijo proti ministru za obrambo januarja 1995, vojaško vmešavanje $v$ civilne zadeve v javnih medijih v obdobju 1993-1994, spore med predsednikom republike in ministrom za obrambo o kompetencah v letih 1993 in 1994 ter afero Depala vas spomladi leta 1994 (Malešič, 2003, 4). Vojaški profesionalci so blažili pomanjkanje usposobljenih, profesionalnih civilnih uslužbencev na Ministrstvu za obrambo, kar kaže na zmotno razumevanje civilnega nadzora nad vojsko (USEUCOM, 2000, 26 in 92). Problem je večplasten in lahko med drugim govorimo o nerazumevanju političnih elit (Jelušič 1998, 96) ali nejasni zakonodaji, ki si jo lahko »vsak razlaga po svoje« (Fekonja, 1996, 5). Za razvoj demokratičnih civilnovojaških odnosov obstaja potreba, da politične elite v Sloveniji pridejo do jasnega in nedvoumnega konsenza o ključnih vprašanjih nacionalne varnosti in obrambe (Grizold, 1997).

2 Greystone (2001, 5-13) na primer v svojem poročilu navaja politične vplive na področju upravljanja kadrov na Ministrstvu za obrambo, centralizirano in podrobno kontrolo vojaških izdatkov, omejeno avtonomnost oboroženih sil in politične razloge za nabavo vojaške opreme.

Učinkovito zakonodajo, ki v Sloveniji »zagotavlja visoko raven demokratičnega in civilnega nadzora obrambnih struktur «, je ugotovila ameriška skupina, ki je analizirala obrambne reforme. Vendar hkrati poudarila, da smo civilni nadzor v Sloveniji pripeljali do »ekstrema«. (USEUCOM, 2000, 26 in 88). Kukec (1996, 37) na primer ugotavlja, da so z Zakonom o obrambi pristojnosti Generalštaba SV tako zožene, da izključujejo možnost odločilnega vpliva načelnika Generalštaba SV na elemente vojaške obrambe, za katere je odgovoren po istem zakonu. Da zakonodajalec določa tudi zadeve, ki so stvar strokovne avtonomije vojske, ugotavlja tudi Kotnik (2007, 5). Krek (2007) je izpostavil vprašanje, ali ima načelnik Generalštaba SV na razpolago zadostna, ustrezna in prilagodljiva sredstva, da lahko zagotavlja popolnjevanje in posledično pripravljenost vojske.
} 
Cilji raziskave so bili iskanje odgovora na vprašanje, kakšne so značilnosti sodobnih civilno-vojaških odnosov v Sloveniji, ocena kakovosti udejanjanja civilnega nadzora v praksi ter ugotavljanje, kako se udejanjanje civilnega nadzora kaže v Slovenski vojski. Da bi ugotovili vzročno-posledično zvezo med civilnim nadzorom in delovanjem vojske, se je bilo treba vprašati, ali uveljavljanje mehanizmov nadzora v praksi dopušča Slovenski vojski razviti svoje sposobnosti za uresničevanje poslanstva oziroma ali lahko na dovolj učinkovit način dosega vojaške cilje. Zato sta bili oblikovani definicija učinkovitosti in struktura analize za ugotavljanje vzročno posledične povezave med nadzorom in učinkovitostjo.

Huntingtonova teorija objektivnega civilnega nadzora nad vojsko je bila uporabljena kot konceptualni okvir za ugotavljanje vrste in kakovosti civilnega nadzora. Kljub kritikam in dopolnilom različnih avtorjev je njeno sporočilo še vedno aktualno objektivni nadzor podpira razvoj vojaškega poklica in učinkovitost vojske za uresničevanje svojega poslanstva. Avtorji, ki so analizirali uporabnost teorije po petdesetih letih njene objave, se strinjajo, da je še vedno najboljše metodološko orodje pri analiziranju sodobnih civilno-vojaških odnosov (Nielsen in Snider, 2009).

\section{UDEJANJANJE CIVILNEGA NADZORA NAD SLOVENSKO VOJSKO}

Raziskava je potrdila, da civilno-vojaški odnosi v Sloveniji sledijo praksi zahodnih demokratičnih ureditev. Podlage za izvajanje civilnega nadzora določajo odnose, pooblastila in odgovornosti med civilnimi in vojaškimi institucijami ter vzpostavljajo pogoje za izvajanje objektivnega nadzora. Obrambna politika in vodenje vojske sta civilni domeni ${ }^{3}$. Civilne oblasti usmerjajo delovanje Slovenske vojske, odobravajo načrte in postavljajo omejitve delovanja. Slovenska vojska sledi političnim ciljem, deluje skladno s svojo vlogo in poslanstvom ter je s stališča civilno-vojaških odnosov poslušna organizacija. $Z$ vojaškim nasvetom sodeluje pri oblikovanju obrambne politike. O svojem stanju in aktivnostih redno seznanja izvajalce civilnega nadzora. Slovenska družba in politika sta zaščiteni od vmešavanja vojske v civilno sfero. S stališča tradicionalne skrbi civilistov - preprečitev neželene vloge vojske v družbi in zagotovitev podrejenosti civilistom, v Sloveniji poteka učinkovit in demokratičen civilni nadzor nad vojsko.

Nosilci institucionalnega civilnega nadzora in Slovenska vojska skoraj v celoti izpolnjujejo svoje vloge v demokratičnem civilno-vojaškem odnosu (preglednici 1 in 2). Vendar v dveh primerih ugotovitvi ni mogoče v celoti pritrditi: na področju določanja meril in standardov za spremljanje in ugotavljanje učinkovitosti Slovenske vojske (bojne pripravljenost) ter krepitve strokovne avtonomnosti Slovenske vojske.

3 Vodenje vojske opredeljuje 42. člen Zakona o obrambi. 
Preglednica 1: Vloga, naloge in odgovornosti nosilcev institucionalnega nadzora

\begin{tabular}{|l|c|}
\hline 1. Formaliziranje vloge Slovenske vojske v družbi; ustavne in zakonske podlage. & $\checkmark$ \\
\hline 2. Odločanje o vojni; odločanje o uporabi Slovenske vojske. & $\checkmark$ \\
\hline 3. Določanje ciljev in strategij na področju varnosti in obrambe; oblikovanje obrambne politike. & $\checkmark$ \\
\hline 4. Določanje meja med vojaško in civilno sfero; določanje vlog in odgovornosti. & $\checkmark$ \\
\hline 5. Spremljanje uresničevanja obrambne politike. & $\checkmark$ \\
\hline 6. Določanje virov (proračun); zagotavljanje pogojev za delovanje in razvoj Slovenske vojske. & $\checkmark$ \\
\hline 7. Definiranje in izvajanje civilnega nadzora nad Slovensko vojsko. & $\checkmark$ \\
\hline $\begin{array}{l}\text { 8. Določanje zahtev, meril in standardov za spremljanje in ugotavljanje učinkovitosti Slovenske } \\
\text { vojske. }\end{array}$ & Delno \\
\hline 9. Vodenje Slovenske vojske; usmerjanje in nadzor delovanja; določanje nalog in omejitev. & $\checkmark$ \\
\hline 10. Določanje številčnega obsega, strukture in opremljenosti Slovenske vojske. & $\checkmark$ \\
\hline 11. Zagotavljanje transparentnosti delovanja in legitimnosti Slovenske vojske v družbi. & $\checkmark$ \\
\hline $\begin{array}{l}\text { 12. Usmerjanje organizacijske kulture; določanje pravil in norm delovanja in vedenja vojaške } \\
\text { organizacije. }\end{array}$ & $\checkmark$ \\
\hline 13. Določanje doktrine; definiranje zahtev in standardov vojaškega izobraževanja in usposabljanja. & $\checkmark$ \\
\hline $\begin{array}{l}\text { 14. Zagotavljanje pogojev za razvoj vojaškega poklica; zagotavljanje strokovne avtonomnosti } \\
\text { Slovenske vojske; spoštovanje strokovnih kompetenc. }\end{array}$ & Delno \\
\hline
\end{tabular}

Preglednica 2:

Vloga, naloge in odgovornosti Slovenske vojske

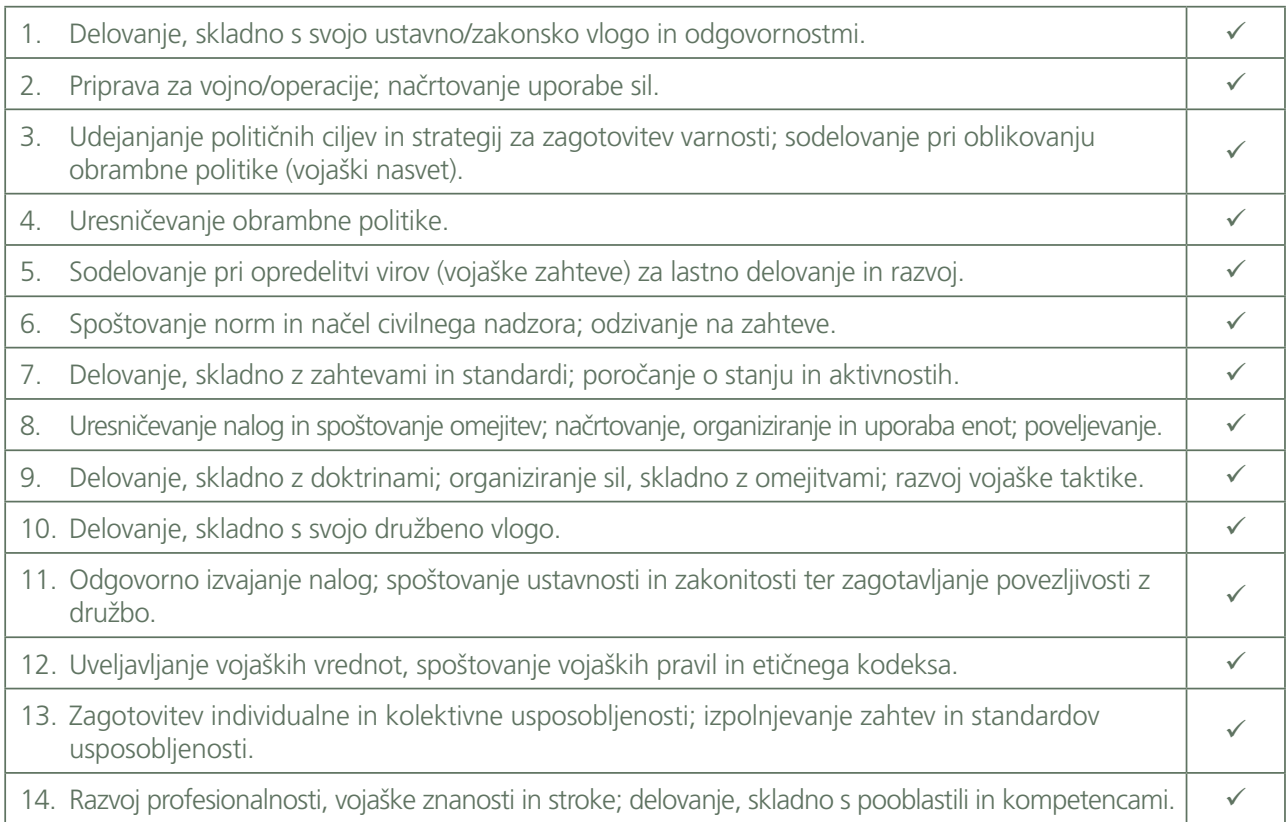


Prisoten je politični interes za izvajanje nadzora, pri čemer imata osrednji vlogi minister za obrambo (vodenje vojske) in Državni zbor (nadzor obrambnega sektorja in vojske). Uporabljajo se predpisane poti izmenjave informacij in poteka medsebojno sodelovanje izvajalcev nadzora. Ti v praksi uveljavljajo mehanizme nadzora, $\mathrm{s}$ katerimi izpolnjujejo svojo vlogo v civilno-vojaškem odnosu (glej preglednico 3), in $\mathrm{z}$ aktivnimi in pasivnimi mehanizmi nadzirajo stanje ter delovanje obrambnega sistema in Slovenske vojske.

Preglednica 3: Uporaba

mehanizmov nadzora v praksi

\begin{tabular}{|c|c|c|c|}
\hline Pasivni mehanizmi & & Aktivni mehanizmi & \\
\hline $\begin{array}{l}\text { 1. Ustavne in zakonske podlage (vloga, } \\
\text { poslanstvo in naloge Slovenske vojske). }\end{array}$ & $\checkmark$ & $\begin{array}{l}\text { 1. »Monitoring (spremljanje stanja } \\
\text { in aktivnosti Slovenske vojske; } \\
\text { spremljanje poročil). }\end{array}$ & $\checkmark$ \\
\hline $\begin{array}{l}\text { 2. Omejevanje moči Slovenske vojske } \\
\text { (določitev obsega, strukture, opreme } \\
\text {..). }\end{array}$ & $\checkmark$ & $\begin{array}{l}\text { 2. Nadziranje in inšpiciranje Slovenske } \\
\text { vojske (računsko sodišče, inšpekcijske } \\
\text { službe, preiskovalne komisije ipd.). }\end{array}$ & $\checkmark$ \\
\hline $\begin{array}{l}\text { 3. Odrejanje proračuna in drugih virov za } \\
\text { delovanje in razvoj Slovenske vojske. }\end{array}$ & $\checkmark$ & $\begin{array}{l}\text { 3. Vodenje in usmerjanje Slovenske } \\
\text { vojske (strateško vodenje; odrejanje } \\
\text { ciljev, načel, nalog in omejitev } \\
\text { delovanja, odobravanje načrtov ipd.). }\end{array}$ & $\checkmark$ \\
\hline $\begin{array}{l}\text { 4. Oblikovanje kulture vojaške } \\
\text { organizacije (pravila službe v Slovenski } \\
\text { vojski, vojaške vrednote, vojaška etika). }\end{array}$ & $\checkmark$ & $\begin{array}{l}\text { 4. Sankcioniranje »neposlušnosti« } \\
\text { (disciplinski ukrepi, javno grajanje, } \\
\text { omejevanje avtonomnosti idr.) }\end{array}$ & $x$ \\
\hline $\begin{array}{l}\text { 5. Določanje pristojnosti in odgovornosti } \\
\text { Slovenske vojske ter načinov } \\
\text { sankcioniranja neposlušnosti. }\end{array}$ & $\checkmark$ & $\begin{array}{l}\text { 5. Civilianizacija Slovenske vojske } \\
\text { (vrinjenje civilnih norm in pristopov). }\end{array}$ & $x$ \\
\hline $\begin{array}{l}\text { 6. Civilianizacija obrambne administracije } \\
\text { (zagotovitev civilne prevlade). }\end{array}$ & $\checkmark$ & $\begin{array}{l}\text { 6. Spodbujanje profesionalizacije } \\
\text { Slovenske vojske. }\end{array}$ & $\checkmark$ \\
\hline $\begin{array}{l}\text { 7. Določanje meja strokovne } \\
\text { avtonomnosti Slovenske vojske. }\end{array}$ & $\checkmark$ & $\begin{array}{l}\text { 7. } \vee \text { ključevanje civilne družbe v nadzor in } \\
\text { razprave o Slovenski vojski. }\end{array}$ & $\checkmark$ \\
\hline $\begin{array}{l}\text { 8. Določanje vojaške kariere (pravila } \\
\text { poviševanja in imenovanja na vojaške } \\
\text { dolžnosti). }\end{array}$ & $\checkmark$ & & \\
\hline $\begin{array}{l}\text { 9. Določanje sistema in zahtev vojaškega } \\
\text { izobraževanja. }\end{array}$ & $\checkmark$ & & \\
\hline
\end{tabular}

Mehanizmi nadzora so usmerjeni v zagotovitev pregleda nad vedenjem Slovenske vojske in $\mathrm{v}$ zagotovitev pogojev za uspešno uresničevanje njenega poslanstva. Slovenska vojska ni soočena z mehanizmi, ki bi povzročali njeno civilianizacijo (uveljavljanje civilnih norm in pristopov), ali $\mathrm{z}$ javno obliko sankcioniranja morebitne neposlušnosti. Z mehanizmi se določajo njena moč (obseg, struktura, oprema in oborožitev), odrejajo viri za njeno delovanje, določajo meje njene strokovne avtonomnosti, njeno poslanstvo in naloge. Z mehanizmi se usmerja kultura 
vojaške organizacije, določajo pravila vojaškega reda in discipline, kadrovanje ter izobraževanje in usposabljanje. Z ukrepi inšpekcijskih, revizijskih in drugih služb, komisij Državnega zbora ter drugih nadzornih organov se zagotavlja podrobnejša informacija o delovanju vojske in izvršne veje oblasti na obrambnem področju.

Značilnosti uresničevanja civilnega nadzora v praksi kažejo, da Slovenija ne izpolnjuje v celoti vseh kriterijev učinkovitega civilnega nadzora (preglednica 4).

\begin{tabular}{|c|c|c|c|}
\hline \multirow{12}{*}{$\begin{array}{r}\text { Preglednica 4: } \\
\text { Učinkovitost } \\
\text { uveljavljanja } \\
\text { civilnega } \\
\text { nadzora v praksi }\end{array}$} & \multirow{2}{*}{$\begin{array}{l}\text { Pogoji za učinkovit civilni nadzor } \\
\text { 1. Praksa in izkušnje izvajanja civilnega nadzora. }\end{array}$} & \multirow{2}{*}{$\begin{array}{l}\text { Izpolnjen } \\
\text { pogoj } \\
\checkmark\end{array}$} & \multirow[t]{2}{*}{ Pomanjkljivost oz. deviacija } \\
\hline & & & \\
\hline & $\begin{array}{l}\text { 2. Izvajalci institucionalnega civilnega } \\
\text { nadzora imajo znanje, interes ter } \\
\text { razumejo svojo vlogo in odgovornosti. }\end{array}$ & Delno & $\begin{array}{l}\text { - pomanjkljivo znanje } \\
\text { - nerazumevanje pomena nadzora (svoje } \\
\text { vloge) }\end{array}$ \\
\hline & $\begin{array}{l}\text { 3. Dobra medsebojna komunikacija med } \\
\text { izvajalci nadzora. }\end{array}$ & Delno & $\begin{array}{l}\text { - »civilno-civilni« konflikti } \\
\text { - omejevanje nadzora } \\
\text { - netransparentnost }\end{array}$ \\
\hline & $\begin{array}{l}\text { 4. Učinkovita integrirana struktura } \\
\text { ministrstva; prevladujejo civilisti. }\end{array}$ & Delno & - integrirana struktura ne obstaja \\
\hline & 5. Obrambno politiko ustvarjajo civilisti. & $\checkmark$ & \\
\hline & $\begin{array}{l}\text { 6. Družba je zaščitena od vmešavanja } \\
\text { vojske v politiko. }\end{array}$ & $\checkmark$ & \\
\hline & $\begin{array}{l}\text { 7. Udejanjanje civilnega nadzora ne vpliva } \\
\text { moteče na delovanje vojske in njeno } \\
\text { učinkovitost. }\end{array}$ & Delno & $\begin{array}{l}\text { - pozne ali nepopolne usmeritve } \\
\text { - nenamenska uporaba vojaškega proračuna }\end{array}$ \\
\hline & $\begin{array}{l}\text { 8. Vojska ima potrebne pristojnosti in } \\
\text { strokovno avtonomnost. }\end{array}$ & Delno & $\begin{array}{l}\text { - ni pooblastil za določanje vojaške taktike } \\
\text { in uporabe vojaške opreme }\end{array}$ \\
\hline & $\begin{array}{l}\text { 9. Vojska sodeluje v procesu oblikovanja } \\
\text { obrambne politike (vojaški nasvet). }\end{array}$ & $\checkmark$ & \\
\hline & 10. Vojska je zaščitena pred politizacijo. & Delno & - tveganje politizacije (kadrovanje) \\
\hline & $\begin{array}{l}\text { 11. Vojska je poslušna organizacija, uveljavlja } \\
\text { politične usmeritve in deluje skladno s } \\
\text { svojo vlogo v družbi. }\end{array}$ & $\checkmark$ & \\
\hline
\end{tabular}

Interes za izvajanje nadzora je skupen vsem nosilcem institucionalnega civilnega nadzora, kar pa ne moremo trditi za njihovo razumevanje svoje vloge in znanja, ki ga potrebujejo. Nekatera vprašanja, s katerimi se je na primer ukvarjal Državni zbor, in tista, ki jih ni bilo na dnevnem redu, kažejo na pomanjkljivo razumevanje parlamentarnega nadzora. ${ }^{4}$ Komunikacija med izvajalci nadzora poteka dobro in

4 Državni zbor se je težiščno ukvarjal z nadzorom izvršne veje oblasti, manj pa s Slovensko vojsko. Odzivanje na stanje $v$ Slovenski vojski je bilo bolj posledica informacij v javnosti in anonimnih pisem kot načrtnega ukvarjanja z vojaško problematiko. 
vidni so že primeri izboljšanja, ${ }^{5}$ vendar obstajajo t. i. »civilno-civilni konflikti«, ko se izvršna oblast upira ali omejuje informacije zakonodajni. ${ }^{6}$

\section{VPLIV CIVILNEGA NADZORA NA UČINKOVITOST SLOVENSKE VOJSKE}

Udejanjanje civilnega nadzora nad vojsko v praksi kaže, da mehanizmi niso popolni in uravnoteženi ter omogočajo konflikte med izvajalci civilnega nadzora, s stališča vojaške organizacije pa lahko omejujejo njeno avtonomno delovanje v vojaški domeni (v okviru pristojnosti) in s tem vzpostavljajo okoliščine, ki omejujejo doseganje sposobnosti ter pogojev za učinkovito uresničevanje poslanstva. Lahko govorimo o občasni krizi objektivnega nadzora nad vojsko in pogojih nastanka subjektivnega nadzora. Pomeni, da lahko skladno s Huntingtonovo teorijo subjektivnega nadzora napori za čim bolj kakovosten civilni nadzor povzročijo negativne učinke za vojaško organizacijo. Na podlagi analize uveljavljanja mehanizmov nadzora v praksi lahko ugotovimo, da je nadzor sicer učinkovit in preprečuje nedemokratično vlogo Slovenske vojske ter zmanjšuje tveganje nenadzorovane uporabe sile, vendar zaradi elementov subjektivnosti in pomanjkljivosti ne krepi učinkovitosti Slovenske vojske. Med dejavniki, ki vplivajo na učinkovitost Slovenske vojske, lahko ugotovimo, da pozitivno vplivajo njena politična nevtralnost, spodbujanje profesionalnosti, zagotavljanje virov in odnosi med civilnimi in vojaškimi voditelji. Pretiravanje z uveljavljanjem mehanizmov nadzora in pomanjkanje strokovne avtonomnosti negativno vplivajo na učinkovitost vojske. Analiza dejavnikov, ki vplivajo na učinkovitost Slovenske vojske, je prikazana v preglednici 5.

Zaradi pomanjkanja znanja, izkušenj ali morebitnega podedovanega strahu od prejšnjega režima je vnema pri vzpostavitvi civilnega nadzora povzročila pomanjkljivo in pretirano uporabo nekaterih mehanizmov nadzora, zaradi česar je imela Slovenska vojska »stransko škodo«. Zato uveljavljanje pretiranega civilnega nadzora ne krepi učinkovitosti vojske pri uresničevanju svojega poslanstva in negativno vpliva na proces vojaškega odločanja. Hkrati lahko takrat, ko se pričakuje njen odziv, povzroči tudi omahovanje ali neustrezno odzivanje. Takšen nadzor lahko omejuje razvoj vojaških zmogljivosti, zmanjšuje kakovost priprav za izvedbo nalog ter dviguje raven tveganja, da naloga ne bo opravljena, kot se pričakuje. Udejanjanje civilnega nadzora v praksi moteče vpliva na delovanje vojske. Nadzorni mehanizmi omejujejo svobodo delovanja načelnika Generalštaba SV in poveljnikov v vojaški domeni oziroma omejujejo uveljavljanje njihovih odgovornosti pri izvajanju vojaških nalog in uporabi dodeljenih virov. Posledica takšnega civilnega nadzora je lahko upočasnjen tempo profesionalizacije Slovenske vojske in razvoja vojaškega poklica, zmanjšanje verodostojnosti načelnika Generalštaba SV ter manjša učinkovitost poveljstev in enot. Pomeni tudi zmanjšanje ugleda in legitimnosti v družbi, prisotno pa je tudi tveganje politizacije vojske.

\footnotetext{
5 Na primer vključevanje Državnega zbora v razprave o uporabi Slovenske vojske v mednarodnih operacijah in na misijah v obdobju 2009-2011.

6 Primer nabave pehotnega oklepnega vozila.
} 
Preglednica 5:

Dejavniki,

ki krepijo

učinkovitost

Slovenske vojske

\begin{tabular}{|l|c|l|}
\hline \multicolumn{1}{|c|}{ Dejavnik } & Krepi & \multicolumn{1}{|c|}{ Opomba } \\
\hline 1. Učinkovit (objektiven) civilni nadzor. & DELNO & Primesi subjektivnega nadzora. \\
\hline \begin{tabular}{l} 
2. $\begin{array}{l}\text { Preudarna (uravnotežena) uporaba } \\
\text { mehanizmov nadzora. }\end{array}$ \\
\hline 3. Politična nevtralnost vojske.
\end{tabular} & NE & Pretirana (vsiljena) uporaba mehanizmov. \\
\hline 4. Spodbujanje profesionalnosti vojske. & DA & \\
\hline 5. Strokovna avtonomnost vojske. & NE & Omejena avtonomnost. \\
\hline 6. Mednarodne organizacije in standardi. & - & Ni bil cilj raziskave. \\
\hline 7. Uspešnost obrambnega sektorja. & - & Ni bil cilj raziskave. \\
\hline 8. Zagotovitev virov (oprema). & DELNO & Manjše zmogljivosti od zahtevanih. \\
\hline 9. Dobre strategije, usmeritve in doktrine. & NE & Pomanjkljive usmeritve in mikromenedžment. \\
\hline $\begin{array}{l}\text { 10. Kakovosten sistem izobraževanja in } \\
\text { usposabljanja. }\end{array}$ & DELNO & Sistem ni celovito definiran. \\
\hline 11. Motiviranje in skrb za legitimnost. & DA & \\
\hline $\begin{array}{l}\text { 12. Dobri odnosi med civilnimi in vojaškimi } \\
\text { voditelji. }\end{array}$ & DA & \\
\hline
\end{tabular}

Značilnosti uveljavljanja civilnega nadzora v praksi in kako se mehanizmi nadzora kažejo v Slovenski vojski (negativni vplivi oziroma posledice na njeno stanje in delovanje), so prikazani v preglednici 6 .

Preglednica 6:

Vplivi

uveljavljanja mehanizmov

nadzora na

Slovensko vojsko

\begin{tabular}{|c|c|}
\hline $\begin{array}{l}\text { Značilnost uveljavljanja mehanizmov } \\
\text { civilnega nadzora }\end{array}$ & $\begin{array}{l}\text { Negativen vpliv/posledica za delovanje } \\
\text { Slovenske vojske }\end{array}$ \\
\hline \multicolumn{2}{|c|}{ 1. Poslanstvo in naloge Slovenske vojske } \\
\hline $\begin{array}{l}\text { - vrhovni poveljnik, omejen v izvajanju poveljniške } \\
\text { funkcije; brez poveljniških pristojnosti odrejanja } \\
\text { nalog } \\
\text { - dvojne linije legitimne avtoritete } \\
\text { - pomanjkljive normativne podlage; ustava ne } \\
\text { opredeljuje nalog in vloge Slovenske vojske; } \\
\text { dvoumnosti glede bojevanja zunaj države in ob } \\
\text { protiterorističnem delovanju } \\
\text { - pomanjkljivo opredeljene naloge v zaščiti in } \\
\text { reševanju }\end{array}$ & $\begin{array}{l}\text { - možnost dvoma v avtoriteto vrhovnega poveljnika } \\
\text { - možnost dvoma o tem, katero avtoriteto upoštevati } \\
\text { ob večjih ambicijah vrhovnega poveljnika } \\
\text { - dvom o odgovornosti poveljujočih - dvojne linije } \\
\text { odgovornosti } \\
\text { - dvom v zakonitost bojnega delovanja v miru } \\
\text { - nepravočasne ali nekakovostne priprave za } \\
\text { izvajanje nalog; možnost izgube ugleda ali } \\
\text { verodostojnosti v javnosti }\end{array}$ \\
\hline \multicolumn{2}{|c|}{ 2. Usmerjanje delovanja in razvoja vojske } \\
\hline $\begin{array}{l}\text { - vsebinsko nekonsistentne in nesodobne strateške } \\
\text { usmeritve; hierarhični nered } \\
\text { _ strateške usmeritve vsebujejo elemente } \\
\text { mikromenedžmenta - posegajo v pristojnosti } \\
\text { drugih političnih ravni }\end{array}$ & $\begin{array}{l}\text { - dvom v aktualnost usmeritev (katere upoštevati) } \\
\text { - dvom v legalnost delovanja ali organiziranja vojske } \\
\text { - pogoji za »civilno-civilne konflikte« (ni neposrednih } \\
\text { posledic za vojsko) }\end{array}$ \\
\hline
\end{tabular}




\begin{tabular}{|c|c|}
\hline $\begin{array}{l}\text { Značilnost uveljavljanja mehanizmov } \\
\text { civilnega nadzora }\end{array}$ & $\begin{array}{l}\text { Negativen vpliv/posledica za delovanje } \\
\text { Slovenske vojske }\end{array}$ \\
\hline \multicolumn{2}{|c|}{ 3. Kadrovanje } \\
\hline $\begin{array}{l}\text { - vgradnja dodatnih varovalk - nezaupanje } \\
\text { v strokovnost predlagatelja (npr. vloga } \\
\text { Obveščevalno-varnostne službe in različnih } \\
\text { odborov) } \\
\text { - kadrovski postopki v nasprotju s predpisi } \\
\text { - povišanja in nagrajevanja vojakov brez upoštevanja } \\
\text { načelnika Generalštaba SV } \\
\text { - kadrovanje v upravni del ministrstva na račun } \\
\text { Slovenske vojske; netransparentnost }\end{array}$ & $\begin{array}{l}\text { - zmanjšanje vloge/pomena načelnika Generalštaba } \\
\text { SV; znižanje avtoritete in verodostojnosti } \\
\text { _ vpliv civilistov (poleg ministra) na kadrovsko politiko } \\
\text { v vojski - možnost civilianizacije in politizacije } \\
\text { vojske } \\
\text { - motenje izvajanja kadrovske politike načelnika } \\
\text { Generalštaba SV; manjša strokovna avtonomnost (v } \\
\text { okviru pooblastil, ki jih ima) } \\
\text { - mogoč neenakopraven položaj vojakov in njihovo } \\
\text { nezaupanje v poštena »pravila igre« } \\
\text { - odliv sposobnih kadrov iz vojske in s tem } \\
\text { zmanjšane sposobnosti }\end{array}$ \\
\hline \multicolumn{2}{|c|}{ 4. Opremljanje } \\
\hline $\begin{array}{l}\text { - podrobno opredeljevanje (mikromenedžment) in } \\
\text { poseganje v pristojnosti drugih političnih ravni } \\
\text { - politične zahteve ali omejitve za spremembo } \\
\text { vojaških zahtev/nasvetov } \\
\text { - nabava opreme, ki ne izpolnjuje vojaških zahtev } \\
\text { - netransparentnost; zavajanje javnosti } \\
\text { - oviranje parlamentarnega nadzora } \\
\text { - nizka raven dialoga med izvršno in zakonodajno } \\
\text { vejo oblasti; vzajemno nezaupanje } \\
\text { - dvom v zakonitost podlag; morebitno zavajanje } \\
\text { nosilcev nadzora in javnosti }\end{array}$ & $\begin{array}{l}\text { - omejevanje svobode odločanja drugih ravni; pogoji } \\
\text { za »civilno-civilne konflikte« (ni neposrednih } \\
\text { posledic za vojsko) } \\
\text { - vprašanje meja lojalnosti civilnim avtoritetam } \\
\text { - prilagajanje na nove zahteve; oblikovanje novih } \\
\text { nasvetov pod političnim pritiskom (manjša } \\
\text { strokovnost); dvom v notranji ali zunanji javnosti } \\
\text { v vojaško strokovnost in verodostojnost } \\
\text { - negiranje/omejevanje strokovne avtonomnosti } \\
\text { - manjše sposobnosti - manjša bojna moč }\end{array}$ \\
\hline \multicolumn{2}{|c|}{ 5. Financiranje } \\
\hline $\begin{array}{l}\text { - podrobno opredeljevanje financ za taktično raven } \\
\text { (mikromenedžment) } \\
\text { - nenamenska in nezakonita uporaba vojaških } \\
\text { sredstev } \\
\text { - odliv sredstev drugim državnim organom in } \\
\text { organizacijam; netransparentna poraba } \\
\text { - podroben nadzor porabe; pretiravanje z mehanizmi } \\
\text { nadzora }\end{array}$ & $\begin{array}{l}\text { - zmanjševanje strokovne avtonomnosti in svobode } \\
\text { uporabe lastnih virov } \\
\text { - nestabilno načrtovanje in prilagajanje financiranja } \\
\text { lastne dejavnosti } \\
\text { - manjša sposobnost (manj denarja za opravljanje } \\
\text { dejavnosti ali vzdrževanje tehnike) } \\
\text { - vojska nosi breme varčevanja }\end{array}$ \\
\hline \multicolumn{2}{|c|}{ 6. Usposabljanje } \\
\hline $\begin{array}{l}\text { - minister za obrambo predpisuje programe } \\
\text { usposabljanja, taktična navodila in navodila za } \\
\text { uporabo opreme in oborožitve } \\
\text { - zakon omogoča postavitve na dolžnosti } \\
\text { neusposobljenih pripadnikov Slovenske vojske } \\
\text { - karierne poti častnikov ne določajo civilne } \\
\text { avtoritete }\end{array}$ & $\begin{array}{l}\text { - ni strokovne avtonomnosti na področju, ki je } \\
\text { v celoti vojaška domena } \\
\text { - morebiten negativni vpliv na učinkovitost delovanja } \\
\text { in vprašanje o verodostojnosti (npr. poveljujoči brez } \\
\text { kompetenc) } \\
\text { - možnost nesistemskih zahtev/pogojev v karieri; } \\
\text { težave načrtovanja kariere pripadnikov Slovenske } \\
\text { vojske v daljšem obdobju in mogoča neenakost, } \\
\text { če zahteve niso konsistentne; posledično težave } \\
\text { profesionalizacije }\end{array}$ \\
\hline \multicolumn{2}{|c|}{ 7. Pripravljenost } \\
\hline $\begin{array}{l}\text { - navodilo za ugotavljanje je v pristojnosti ministra, } \\
\text { vendar merila (standarde) določa načelnik } \\
\text { Generalštaba SV }\end{array}$ & $\begin{array}{l}\text { - možnost dvoma v verodostojnost poročila o } \\
\text { pripravljenosti (ocenjeni se ocenjuje po lastnih } \\
\text { merilih) }\end{array}$ \\
\hline
\end{tabular}




\begin{tabular}{|c|c|}
\hline $\begin{array}{l}\text { Značilnost uveljavljanja mehanizmov } \\
\text { civilnega nadzora }\end{array}$ & $\begin{array}{l}\text { Negativen vpliv/posledica za delovanje } \\
\text { Slovenske vojske }\end{array}$ \\
\hline \multicolumn{2}{|c|}{ 8. Delovanje } \\
\hline $\begin{array}{l}\text { - pozne odločitve o uporabi Slovenske vojske } \\
\text { - nejasni cilji sodelovanja v določenih operacijah } \\
\text { v tujini } \\
\text { - operativno-taktične usmeritve; podrobno } \\
\text { opredeljevanje nalog in dodeljevanje nalog mimo } \\
\text { linije poveljevanja (mikromenedžment) }\end{array}$ & $\begin{array}{l}\text { - pomanjkanje časa za kakovostne priprave; } \\
\text { morebitna manjša sposobnost za izvedbo naloge } \\
\text { (tveganje manjše učinkovitosti); prilagajanje priprav } \\
\text { in izvedbe v razpoložljivem času } \\
\text { - samoiniciativna organiziranost priprav; možnosti } \\
\text { neracionalne porabe virov } \\
\text { - težave razumevanja razlogov za delovanje ali } \\
\text { poslanstva; težave pri motiviranju podrejenih } \\
\text { - zmanjšanje strokovne avtonomnosti; ni svobode } \\
\text { delovanja v vojaški domeni } \\
\text { - vzporedno vodenje; zmanjšanje avtoritete } \\
\text { poveljujočih (kršenje vojaških pravil - linije } \\
\text { poveljevanja) }\end{array}$ \\
\hline
\end{tabular}

Sklep V Republiki Sloveniji je že skoraj 25-letna praksa uveljavljanja civilnega nadzora nad vojsko skladno z demokratičnimi standardi, vendar značilnost uveljavljanja civilnega nadzora $\mathrm{v}$ praksi kaže na pomanjkljivo razumevanje vloge izvajalcev nadzora, pomanjkanje kulture političnega dialoga in pretiravanje uveljavljanja mehanizmov nadzora zaradi povečanja njegove učinkovitosti. Raziskava je potrdila hipotezo, da udejanjanje civilnega nadzora nad vojsko v Republiki Sloveniji povzroča prilagajanje delovanja Slovenske vojske, pri čemer obstaja tveganje zmanjšane verodostojnosti ali sposobnosti uresničevanja njenega osnovnega poslanstva. Nadzor je po Huntingtonu objektiven, vendar značilnosti subjektivnega nadzora nad vojsko v želji po čim bolj učinkovitem nadzoru v praksi pomenijo, da zato ni bolj kakovosten, temveč je večja verjetnost, da so posledice za vojsko negativne. Slovenija je primer, kako ima lahko demokratizacija civilnega nadzora negativne posledice, če izvajalci nadzora niso pozorni na potrebe vojske, ki se trudi vzpostaviti učinkovito vojaško organizacijo, sposobno izpolnjevati svojo ustavno in zakonsko vlogo v družbi.

Treba je razumeti, da civilni nadzor ni namenjen samo podreditvi vojske civilnim oblastem, temveč tudi krepitvi njene učinkovitosti. »Nadzorniki« bi se morali zavedati negativnih vplivov, ki jih ima lahko pretiran ali vsebinsko neustrezen nadzor nad vojsko. Nepazljiva ali nepreudarna uporaba nadzornih mehanizmov, ki škodujejo verodostojnosti načelnika Generalštaba SV, verodostojnosti vojaške stroke ali vojske kot celote ter zmanjšujejo pripravljenost vojske, lahko povzročijo neuspešno uresničevanje poslanstva in nezadovoljstvo v Slovenski vojski. Nezadovoljstvo pa lahko povzroči civilno-vojaška trenja in nestabilne civilno-vojaške odnose. Torej ravno nasprotno temu, kar je namen demokratičnega nadzora nad oboroženimi silami. 
1. Arnejčič, B. in Vuk I., 2001. Civil-military relations in Slovenia: aspects, factors, problems. V Civil-military relations in south-east Europe, ur. Plamen Pantev, 180-196. Sofia: National defense academy. Institute for security and international studies.

2. Bebler, A., 1992. Jugoslovanska ljudska armada in razpad Jugoslavije. V Razpotja nacionalne varnosti. Obramboslovne raziskave v Sloveniji, ur. Anton Grizold, 45-57. Ljubljana: FDV.

3. Bebler, A., 1997. The region wide perspective on post-communist civil-military relations. $V$ Civil-military relations in post-communist states, Central and Eastern Europe in transition, ur. Anton Bebler, 65-76. London, Praeger.

4. Betz, J. D., 2004. Civil-military relations in Russia and eastern Europe. London: Routledge Curzon.

5. Bland, L. D., 2001. Patterns in liberal democratic civil-military relations. Armed forces \& Society 27 (4): 525-540.

6. Boene, B. in Bredow, W., 1999. The military in common-risk societies; elements of comparison among nine countries of west, central and east Europe. V Military and Society in 21st century Europe. A comparative analysis, ur. Jürgen Kuhlmann in Jean Callaghan, 305-331. George C. Marshall, European center for security studies. London: Transaction publishers.

7. Born, H. in drugi. 2006. Patterns of democratic governance of civil-military relations. $V$ Civil-military relations in Europe. Learning from crisis and institutional change, ur. Hans Born, Marina Caparini, Karl Haltiner in Jürgen Kuhlmann, 235-255. New York: Routledge Military Studies.

8. Cottey, A., Edmunds, T. in Forster, A., 2002. The second generation problematic: rethinking democracy and civil-military relations. Armed Forces \& Society 29 (1): 31-56.

9. Cottey, A., 2000. A framework for understanding democratic control of armed forces in post-communist Europe. V Civil-military relations and defense planning: challenges for central and eastern Europe in the new era. Conference report, ur. Andrew Cottey, Thimoty Edmunds in Anthony Forster, 4. Sussex: Economic and social research council.

10. Edmunds, T., 2004. Defens reforms in Croatia and Serbia-Montenegro. Adelphi papers. New York: Routledge.

11. Fekonja, M., 1996. Med politiko, dokumenti in resničnostjo. Obramba 6/96: 3-5.

12. Furlan, B., 2012. Civilni nadzor in delovanje vojske. Doktorska disertacija. Ljubljana: FDV.

13. Furlan, B., 2015. Neučinkovitost vojske kot pokazatelj pomanjkljivosti civilnega nadzora (1). Sodobni vojaški izzivi št. 17/2, maj 2015.

14. Greystone, N., 2001. Democratic control of the armed forces of Slovenia. A progress report. V Civil-military relations in post-cold war Europe, ur. Herd Greame, 5-13. Camberly: Conflict studies research center.

15. Grizold, A., 1994. Civilian supervision of the military in Slovenia. The Public 1 (4): 87-94.

16. Grizold, A., 1997. Civil-military relations in Slovenia. V Civil-military relations in postcommunist states, Central and Eastern Europe in transition, ur. Anton Bebler, 101-109. London, Praeger.

17. Hendrickson, C. R., 2002. Expanding NATO: the case for Slovenia. Parameters 3: 64-76.

18. Jelušič, L., 1998. Spreminjanje odnosov med vojaštvom in civilnim okoljem $v$ postsocializmu. V Perspektive sodobne varnosti, ur. Anton Grizold., 76-96. Ljubljana: FDV.

19. Kotnik, I., 2007. Erjavec pošilja Viranta po kostanj v žerjavico. Delo (17. 5. 2007).

20. Krek, U., 2007. Reforma obrambnih reform. Delo.

21. Kukec, I., 1996. Doktrina vojaške obrambe. Vojstvo 96 (1): 19-60.

22. Malešič, M., 2003. Executive decisions and divisions: disputing competences in civilmilitary relations in Slovenia. Ženeva: Geneva centre for the democratic control of armed forces. 
23. Nielsen, C. S. in Snider M. D., 2009. American civil-military relations. The soldier and the state in a new era. Baltimore: The Johns Hopkins University Press.

24. Prebilič, V., 2007. Civilno vojaški odnosi po vstopu v Nato in EU-praktični vidik civilnega nadzora na OS z analizo razmerij med zakonodajno in izvršno oblastjo ter evroatlantskimi povezavami Severnoatlantsko zavezništvo in EU. Raziskovalni projekt šifra. M5-0187. Ljubljana: Obramboslovni raziskovalni center FDV.

25. US EUCOM, ASDIS. 2000. The Republic of Slovenia-Defense reform study. Štutgart. Washington.

26. Zorc, M., 2005. Predsednik Republike Slovenije kot vrhovni poveljnik obrambnih sil Republike Slovenije. V Sodobno vojaštvo in družba, ur. Anton Bebler, 102-169. Ljubljana: FDV. 